\title{
Urea-hydrogen peroxide prompted the selective and controlled oxidation of thioglycosides into sulfoxides and sulfones
}

\author{
Adesh Kumar Singh, Varsha Tiwari, Kunj Bihari Mishra, Surabhi Gupta \\ and Jeyakumar Kandasamy ${ }^{*} \S$
}

\author{
Full Research Paper \\ Address: \\ Department of Chemistry, Indian Institute of Technology, Banaras \\ Hindu University, Varanasi-221005, India \\ Email: \\ Jeyakumar Kandasamy* - jeyakumar.chy@iitbhu.ac.in \\ * Corresponding author \\ § Tel.: +91-0542-6702879; fax: +91- 0542-6702876 \\ Keywords: \\ monosaccharides; oxidation; sulfones; sulfoxides; thioglycosides; \\ urea-hydrogen peroxide
}

\author{
Beilstein J. Org. Chem. 2017, 13, 1139-1144. \\ doi:10.3762/bjoc. 13.113 \\ Received: 23 March 2017 \\ Accepted: 23 May 2017 \\ Published: 13 June 2017 \\ This article is part of the Thematic Series "Biomolecular systems". \\ Guest Editor: P. H. Seeberger \\ (c) 2017 Singh et al.; licensee Beilstein-Institut. \\ License and terms: see end of document.
}

\begin{abstract}
A practical method for the selective and controlled oxidation of thioglycosides to corresponding glycosyl sulfoxides and sulfones is reported using urea-hydrogen peroxide (UHP). A wide range of glycosyl sulfoxides are selectively achieved using 1.5 equiv of UHP at $60{ }^{\circ} \mathrm{C}$ while corresponding sulfones are achieved using 2.5 equiv of UHP at $80{ }^{\circ} \mathrm{C}$ in acetic acid. Remarkably, oxidation susceptible olefin functional groups were found to be stable during the oxidation of sulfide.
\end{abstract}

\section{Introduction}

Organosulfur compounds such as sulfides, sulfoxides and sulfones are useful intermediates for the construction of highly functionalized natural products $[1,2]$. Sulfur moieties are found in several therapeutically important molecules that possess antibacterial, antifungal, anti-ulcer, anti-atherosclerotic, antihypertensive activities, etc. [3,4]. Sulfur compounds also play an important role in carbohydrate synthesis. Thioglycosides, glycosyl sulfoxides and sulfones have been widely used as glycosyl donors in oligosaccharide synthesis which can be activated under mild reaction conditions [5-10]. Glycosyl sulf- oxide donors usually provide excellent anomeric selectivity during the synthesis of various glycosyl linkages not only in solution phase but also in solid-phase oligosaccharide synthesis $[6-9,11]$. Glycosyl sulfones were also used as donors in the preparation of various $C$ - and $O$ - linked oligosaccharides and functionalized glycols $[8,9,12]$. In addition, glycosyl sulfones are known to be potential glycosyltransferase inhibitors [13].

Glycosyl sulfoxides and sulfones are prepared from the corresponding sulfides using various oxidizing reagents [5-7,10]. Al- 
though a number of oxidation methods were developed for the oxidation of simple organic sulfides to corresponding sulfoxides and sulfones [14-16], there are only limited reports available for the preparation of glycosyl sulfoxides and sulfones from corresponding thioglycosides [5-7,17-23]. Moreover, there is no report available where a given oxidant is suitable for controlled oxidation of thioglycosides to glycosyl sulfoxides and sulfones selectively by altering the reaction conditions. It is also observed that thioglycoside oxidation suffers from low yields, poor selectivity (i.e., sulfoxide vs sulfone), use of inconvenient reaction conditions and expensive oxidants, intolerance of other oxidation susceptible functional groups, etc. Thus, developing a mild and efficient method for the controlled oxidation of sulfides to corresponding glycosyl sulfoxides and sulfones, is of great interest.

The utility of hydrogen peroxide-solid adducts in organic synthesis is well explored [24]. Most of them are found to be stable which can be easily handled and stored. One such solid adduct is urea-hydrogen peroxide (UHP) which is considered to be a safer and efficient alternative to high concentrated aqueous hydrogen peroxide solution [25]. In addition, UHP is also commercially available, inexpensive and nontoxic. The application of UHP as oxidant is well explored in various solution- as well as solid-phase organic syntheses [25-28]. In fact, we have recently reported the oxidation of arylboronic acids into corresponding phenols by using UHP as a selective oxidizing agent [29]. In continuation to our effort in developing green methodologies [29-33], here we disclose an efficient and practical method for the conversion of glycosyl sulfides into sulfoxides and sulfones in a selective and controlled manner using urea-hydrogen peroxide in acetic acid.

\section{Results and Discussion}

Initially, phenyl-2,3,4,6-tetra- $O$-acetyl-1-thio- $\beta$-D-glucopyranoside (1) was chosen as a substrate for the optimization study and oxidation was performed in various solvents at different temperatures in the presence of urea-hydrogen peroxide (UHP) (Table 1). Polar aprotic solvents such as dichloromethane and acetonitrile gave a negligible amount of corresponding sulfoxide (1a) while no sulfone (1b) was detected at room temperature even after 6 hours (Table 1, entries 1 and 2). However, protic solvents such as methanol, ethanol, tert-butanol and acetic acid were found to be relatively efficient media for the oxidation when compared with dichloromethane and acetonitrile (Table 1, entries 3-6). Among them, acetic acid gave $37 \%$ of the glycosyl sulfoxide (1a) after $6 \mathrm{~h}$ at room temperature with one equiv of UHP (Table 1, entry 6) while alcoholic

Table 1: Optimization of reaction conditions. ${ }^{a}$

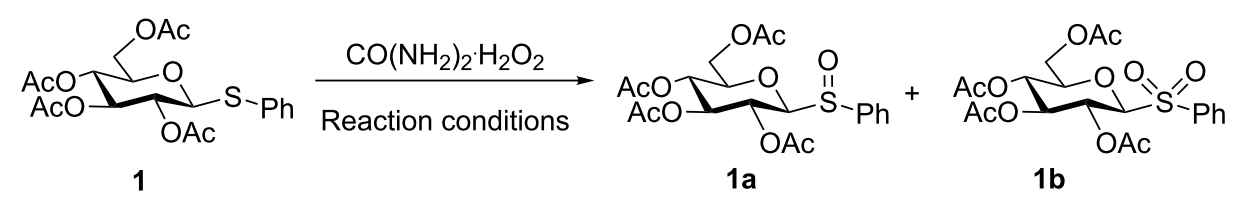

\begin{tabular}{|c|c|c|c|c|c|c|}
\hline \multirow[t]{2}{*}{ Entry } & \multirow{2}{*}{$\begin{array}{l}\text { UHP } \\
\text { (equiv) }\end{array}$} & \multirow[t]{2}{*}{ Solvent } & \multirow[t]{2}{*}{ Temperature } & \multirow[t]{2}{*}{ Time } & \multicolumn{2}{|c|}{ Yield $(\%)^{b}$} \\
\hline & & & & & $1 a^{c}$ & $1 b$ \\
\hline 1 & 1.0 & $\mathrm{DCM}$ & $\mathrm{rt}$ & $6 \mathrm{~h}$ & $<5$ & n.d. \\
\hline 2 & 1.0 & $\mathrm{CH}_{3} \mathrm{CN}$ & $\mathrm{rt}$ & $6 \mathrm{~h}$ & $<10$ & n.d. \\
\hline 3 & 1.0 & $\mathrm{MeOH}$ & $\mathrm{rt}$ & $6 \mathrm{~h}$ & 12 & n.d. \\
\hline 4 & 1.0 & $\mathrm{EtOH}$ & $\mathrm{rt}$ & $6 \mathrm{~h}$ & 15 & n.d. \\
\hline 5 & 1.0 & $t-\mathrm{BuOH}$ & $\mathrm{rt}$ & $6 \mathrm{~h}$ & 13 & n.d. \\
\hline 6 & 1.0 & $\mathrm{AcOH}$ & $\mathrm{rt}$ & $6 \mathrm{~h}$ & 37 & n.d. \\
\hline 7 & 1.5 & $\mathrm{AcOH}$ & $\mathrm{rt}$ & $6 \mathrm{~h}$ & 64 & n.d. \\
\hline 8 & 1.5 & $\mathrm{AcOH}$ & $40^{\circ} \mathrm{C}$ & $6 \mathrm{~h}$ & 90 & n.d. \\
\hline 9 & 1.5 & $\mathrm{AcOH}$ & $60^{\circ} \mathrm{C}$ & $2 \mathrm{~h}$ & 92 & $<5$ \\
\hline 10 & 1.5 & $\mathrm{AcOH}$ & $80^{\circ} \mathrm{C}$ & $2 \mathrm{~h}$ & 87 & 7 \\
\hline 11 & 2.0 & $\mathrm{AcOH}$ & $80^{\circ} \mathrm{C}$ & $3 \mathrm{~h}$ & 65 & 31 \\
\hline 12 & 2.5 & $\mathrm{AcOH}$ & $80^{\circ} \mathrm{C}$ & $10 \mathrm{~h}$ & $<5$ & 93 \\
\hline
\end{tabular}

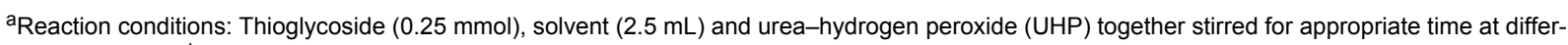
ent temperature. ${ }^{b}$ Isolated Yield. ${ }^{c}$ Obtained as $R$ and $S$ mixture. 
solvents gave a low yield. When we increased the amount of UHP to 1.5 equiv, the reaction provides only $64 \%$ of the desired sulfoxide at room temperature (Table 1 , entry 7 ). Therefore, the reaction was further investigated at elevated temperatures using 1.5 equiv of UHP (Table 1, entries 8 and 9) in acetic acid. Interestingly, the reaction was driven to completion with the desired sulfoxide (1b) in $92 \%$ yield within $2 \mathrm{~h}$ at $60{ }^{\circ} \mathrm{C}$ (Table 1, entry 9). It is also worth noting that less than $5 \%$ of the corresponding sulfone was detected in the crude product by ${ }^{1} \mathrm{H}$ NMR under these conditions.

Considering the importance of glycosyl sulfones, we further investigated the suitable conditions for the direct oxidation of sulfide to sulfone using UHP in acetic acid. For this, we have tried the reactions with an increased amount of UHP and elevated temperature (Table 1, entries 10-12). It was observed that with 1.5 to 2.0 equiv of $\mathrm{UHP}$ at $80^{\circ} \mathrm{C}$, the reaction yields a mixture of sulfoxide 1a and sulfone 1b (Table 1, entries 10-11) in different ratio. However, by increasing the amount of UHP to 2.5 equiv, sulfide $\mathbf{1}$ is fully converted to the corresponding sulfone $1 \mathrm{~b}$ in an excellent yield, i.e., $93 \%$ in $10 \mathrm{~h}$ at $80{ }^{\circ} \mathrm{C}$ (Table 1 , entry 12).

With optimized conditions in hand (Table 1, entries 9 and 12), a controlled oxidation of various glycosyl sulfides to corresponding sulfoxides and sulfones was studied with urea-hydrogen peroxide in acetic acid (Table 2). For this study, a series of $\alpha$ and $\beta$-thioglycosides, 1-19 were initially prepared by using literature procedures (see Supporting Information File 1). In addition, structurally diverse aglycone moieties were selected in order to study the breadth and scope of the current methodology. Initially, the oxidation of $O$-acetylated and benzoylated phenyl and $p$-tolyl thioglucopyranosides was examined (Table 2, entries 1-4). These aryl sulfides underwent oxidation very efficiently to provide the corresponding sulfoxides $1 \mathbf{a}-\mathbf{4 a}$ in excellent yields, i.e., $85-93 \%$ under optimized conditions. Similarly,

Table 2: Controlled oxidation of various thioglycosides to corresponding sulfoxides and sulfones using urea-hydrogen peroxide (UHP) ${ }^{\text {a,b }}$.

1

2

3

4

5

6
Substrate

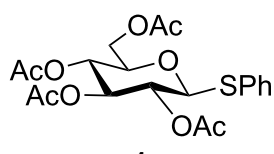

1

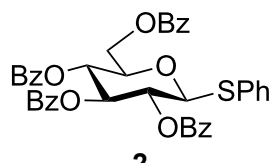

2

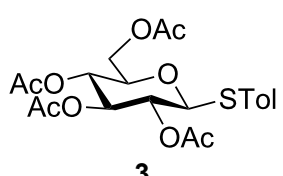

3
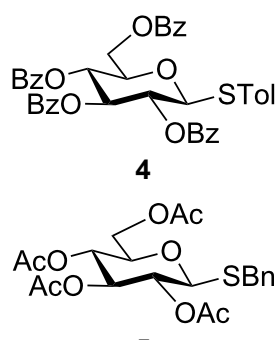

5

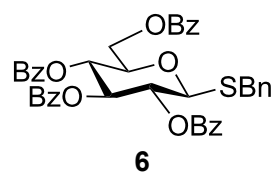

$2 \mathrm{~h}$

92

85

$10 \mathrm{~h}$

91

$2 \mathrm{~h}$

$2 \mathrm{~h}$

$2 \mathrm{~h}$

$1.5 \mathrm{~h}$

$1.5 \mathrm{~h}$

$10 \mathrm{~h}$

93

93

$10 \mathrm{~h}$

94

89

$10 \mathrm{~h}$

92

$8 \mathrm{~h}$

94

87

$8 \mathrm{~h}$

89
Sulfoxide $(\mathbf{a})^{\mathrm{c}}$

Yield (\%) 

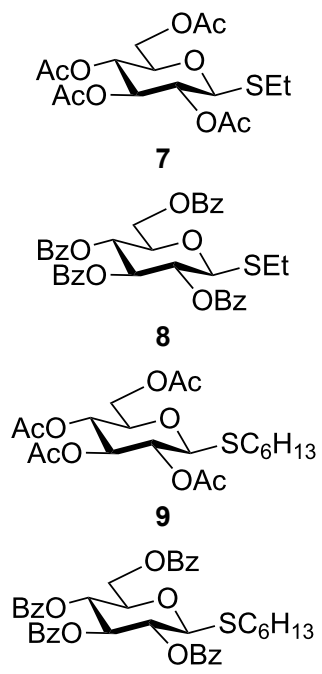

10

11

12

15

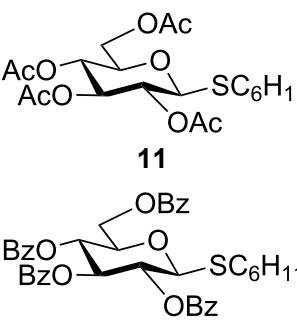

12

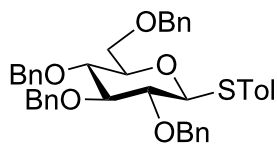

13

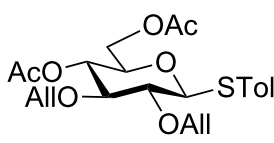

14

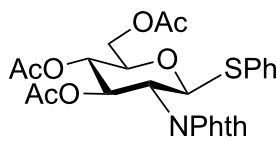

15

16

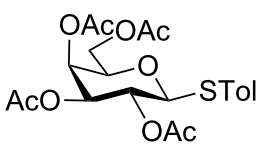

16

17
$1.5 \mathrm{~h}$

$1.5 \mathrm{~h}$

$2.0 \mathrm{~h}$

92

$8 \mathrm{~h}$

94

$2.0 \mathrm{~h}$

$2 \mathrm{~h}$

90

$10 \mathrm{~h}$

92

$2 \mathrm{~h}$

87

$10 \mathrm{~h}$

90

$1.5 \mathrm{~h}$

82

$6 \mathrm{~h}$

64

$2 \mathrm{~h}$

$2.5 \mathrm{~h}$

91

$8 \mathrm{~h}$

82

$2.5 \mathrm{~h}$

80

$10 \mathrm{~h}$

89

$2.5 \mathrm{~h}$

77

$11 \mathrm{~h}$

87 
18

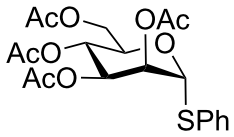

18

19

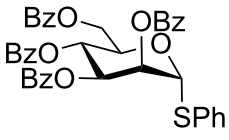

$2 \mathrm{~h}$

$2 \mathrm{~h}$

aReaction Conditions: Thioglycoside $(0.25 \mathrm{mmol})$, acetic acid $(2.5 \mathrm{~mL})$ and UHP (1.5 equiv) stirred at $60{ }^{\circ} \mathrm{C}$. beaction conditions: Thioglycoside $(0.25$ $\mathrm{mmol})$, acetic acid $(2.5 \mathrm{~mL})$ and UHP (2.5 equiv) stirred at $80^{\circ} \mathrm{C}$. ${ }^{\circ}$ Obtained as $R$ and $S$ mixture. ${ }^{\mathrm{d}}$ Isolated Yield.

corresponding glycosyl sulfones $\mathbf{1 b}-\mathbf{4 b}$ were also achieved in 91-94\% yield by simply altering the reaction conditions as described in the optimization study.

We further examined the oxidation of $O$-acetyl- (Ac) and benzoyl- (Bz) protected benzyl thioglucopyranosides, which showed a good selectivity during the controlled oxidation with UHP and provided $>87 \%$ and $>89 \%$ of the desired sulfoxides (5a and $6 \mathbf{a}$ ) and sulfones (5b and $\mathbf{6 b}$ ), respectively (Table 2, entries 5 and 6). Similar to phenyl and benzyl sulfides, alkyl sulfides such as ethyl, $n$-hexyl and cyclohexyl glycosyl sulfides were also successfully oxidized in a controlled and selective manner with equal efficiency (Table 2, entries 7-12).

Having studied the oxidation of electron deficient thioglucopyranosides, we further investigated the oxidation of $O$-benzyl protected 4-methylphenyl thioglycoside 13 under optimized conditions (Table 2, entry 13). This substrate was found to be more reactive than $O$-acetylated and benzoylated thioglycosides and gave the sulfoxide in a good yield within $1.5 \mathrm{~h}$. However, corresponding sulfone was obtained in a moderated yield due to instability which undergoes partial amount of decomposition.

In general, olefins functional groups are known to undergo epoxidation or dihydroxylation with different oxidizing agents (e.g. $m$-CPBA, $t$-BuOOH, oxone, etc.) [34]. Therefore, the scope of this methodology was further investigated with oxidation of allyl group protected thioglycoside 14 (Table 2, entry 14). Remarkably, allyl groups were found to be very stable during the oxidation while sulfide underwent selective oxidation to corresponding sulfoxide and sulfone in $89 \%$ and $91 \%$, respectively. Further, we have studied the oxidation of protected glucosamine thioglycoside (Table 2, entry 15) which provided $91 \%$ of sulfoxide and $82 \%$ of sulfone.
The scope of the oxidation reaction was subsequently investigated with other monosaccharides such as galacto and mannothioglycosides under optimized conditions (Table 2). Similar to glucopyranosides, galacto and mannothioglycosides 16-19 were successfully oxidized to corresponding sulfoxides and sulfones in good to excellent yields (Table 2, entries 16-19). Overall, sulfoxides were achieved within the time period of 1.5-2.5 h while sulfones were obtained in 6-11 h.

\section{Conclusion}

In conclusion, we have developed a practical method for the selective and controlled oxidation of thioglycosides to corresponding glycosyl sulfoxides and sulfones using the stable, inexpensive and commercially available oxidant urea-hydrogen peroxide (UHP). Glycosyl sulfoxides were achieved using 1.5 equiv of UHP at $60{ }^{\circ} \mathrm{C}$ while sulfones were achieved using 2.5 equiv of UHP at $80^{\circ} \mathrm{C}$. Remarkably, oxidation susceptible olefin functional groups were found to be stable during the sulfide oxidation.

\section{Supporting Information}

\section{Supporting Information File 1}

Experimental part and NMR spectra.

[http://www.beilstein-journals.org/bjoc/content/

supplementary/1860-5397-13-113-S1.pdf]

\section{Acknowledgements}

J. K. gratefully acknowledges DST-India for young scientist start-up research grant (YSS/2014/000236). J. K. also acknowledges Max-Planck Society-Germany and DST-India (DST/INT/ MPG/P-09/2016) for financial support through Indo-Max Planck partner group project. A. K. S acknowledges CSIR for junior research fellowship (JRF). S. G acknowledges IIT (BHU) 
for a research fellowship. J. K. thanks to Mr. Albert Pape and Dr. K. Murugan for a helpful discussion during the manuscript preparation. J. K. thanks Central Instrumentation Facility Center (CIFC)-IIT BHU for the NMR facilities.

\section{References}

1. Rayner, C. M. Advances in Sulfur Chemistry; Jai Press: Stamford Connecticut, 2000.

2. Cremlyn, R. J. An introduction to oranosulfur chemistry; Wiley: New York, 1996.

3. Feng, M. H.; Tang, B. Q.; Liang, S. H.; Jiang, X. F. Curr. Top. Med. Chem. 2016, 16, 1200. doi:10.2174/1568026615666150915111741

4. Patani, G. A.; LaVoie, E. J. Chem. Rev. 1996, 96, 3147. doi:10.1021/cr950066q

5. Levy, D. E.; Fügedi, P. The Organic Chemistry of Sugars; CRC Press, Taylor \& Francis Group, 2005.

6. Aversa, M. C.; Barattucci, A.; Bonaccorsi, P. Tetrahedron 2008, 64, 7659. doi:10.1016/j.tet.2008.05.051

7. Khan, S. H. Modern Methods in Carbohydrate Synthesis; CRC Press, Taylor \& Francis Group, 1996.

8. Bennett, C. S. Selective Glycosylations: Synthetic Methods and Catalysts; Wiley-VCH Verlag GmbH \& Co. KGaA, 2017.

9. Werz, D. B.; Vidal, S. Modern Synthetic Methods in Carbohydrate Chemistry: From Monosaccharides to Complex Glycoconjugates; Wiley-VCH Verlag GmbH \& Co. KGaA, 2014.

10. Hanessian, S. Marcel Dekker: New York, 1997.

11. Kahne, D.; Walker, S.; Cheng, Y.; Van Engen, D. J. Am. Chem. Soc. 1989, 111, 6881. doi:10.1021/ja00199a081

12. Najera, C.; Yus, M. Tetrahedron 1999, 55, 10547. doi:10.1016/S0040-4020(99)00600-6

13. Gervay, J.; Flaherty, T. M.; Holmes, D. Tetrahedron 1997, 53, 16355. doi:10.1016/S0040-4020(97)01021-1

14. Kaczorowska, K.; Kolarska, Z.; Mitka, K.; Kowalski, P. Tetrahedron 2005, 61, 8315. doi:10.1016/j.tet.2005.05.044

15. Kowalski, P.; Mitka, K.; Ossowska, K.; Kolarska, Z. Tetrahedron 2005, 61, 1933. doi:10.1016/j.tet.2004.11.041

16. Jeyakumar, K.; Chand, D. K. Tetrahedron Lett. 2006, 47, 4573. doi:10.1016/j.tetlet.2006.04.153

17. Agnihotri, G.; Misra, A. K. Carbohydr. Res. 2006, 341, 275. doi:10.1016/j.carres.2005.11.025

18. Kakarla, R.; Dulina, R. G.; Hatzenbuhler, N. T.; Hui, Y. W.; Sofia, M. J. J. Org. Chem. 1996, 61, 8347. doi:10.1021/jo961478h

19. Wang, Q.; Wei, X.; Liao, K. J.; Li, H.; Meng, X. B.; Li, Z. J. Tetrahedron Lett. 2016, 57, 2277. doi:10.1016/j.tetlet.2016.04.045

20. Nigudkar, S. S.; Demchenko, A. V. Chem. Sci. 2015, 6, 2687. doi:10.1039/C5SC00280J

21. Agnihotri, G.; Misra, A. K. Tetrahedron Lett. 2005, 46, 8113. doi:10.1016/j.tetlet.2005.09.132

22. Chen, M.-Y.; Patkar, L. N.; Chen, H.-T.; Lin, C.-C. Carbohydr. Res. 2003, 338, 1327. doi:10.1016/S0008-6215(03)00164-2

23. Morais, G. R.; Humphrey, A. J.; Falconer, R. A. Tetrahedron 2008, 64, 7426. doi:10.1016/j.tet.2008.05.033

24. Jones, C. W. Applications of Hydrogen Peroxide and Derivatives; Royal Society of Chemistry: Cambridge, 1999.

25. Cooper, M. S.; Heaney, H.; Newbold, A. J.; Sanderson, W. R. Synlett 1990, 533. doi:10.1055/s-1990-21156

26. Varma, R. S.; Naicker, K. P. Org. Lett. 1999, 1, 189. doi:10.1021/ol990522n
27. Caron, S.; Do, N. M.; Sieser, J. E. Tetrahedron Lett. 2000, 41, 2299. doi:10.1016/S0040-4039(00)00165-9

28. Ankudey, E. G.; Olivo, H. F.; Peeples, T. L. Green Chem. 2006, 8, 923. doi:10.1039/B604984B

29. Gupta, S.; Chaudhary, P.; Srivastava, V.; Kandasamy, J. Tetrahedron Lett. 2016, 57, 2506. doi:10.1016/j.tetlet.2016.04.099

30. Chaudhary, P.; Gupta, S.; Popuri, S.; Sabiah, S.; Kandasamy, J. Green Chem. 2016, 18, 6215. doi:10.1039/C6GC02444K

31. Gupta, S.; Chaudhary, P.; Seva, L.; Sabiah, S.; Kandasamy, J. RSC Adv. 2015, 5, 89133. doi:10.1039/C5RA18080E

32. Chaudhary, P.; Gupta, S.; Muniyappan, N.; Sabiah, S.; Kandasamy, J. Green Chem. 2016, 18, 2323. doi:10.1039/C5GC02880A

33. Gupta, S.; Sureshbabu, P.; Singh, A. K.; Sabiah, S.; Kandasamy, J. Tetrahedron Lett. 2017, 58, 909. doi:10.1016/j.tetlet.2017.01.051

34. Bäckvall, J.-E. Modern Oxidation Methods, 2nd ed.; Wiley-VCH: Weinheim, 2010. doi:10.1002/9783527632039

\section{License and Terms}

This is an Open Access article under the terms of the Creative Commons Attribution License

(http://creativecommons.org/licenses/by/4.0), which permits unrestricted use, distribution, and reproduction in any medium, provided the original work is properly cited.

The license is subject to the Beilstein Journal of Organic Chemistry terms and conditions:

(http://www.beilstein-journals.org/bjoc)

The definitive version of this article is the electronic one which can be found at: doi:10.3762/bjoc. 13.113 